\title{
C) HISTSTórICA
}

\section{Apresentação}

É com muita satisfação que apresentamos aos leitores o Dossiê 'História Social do Crime'. Sabemos que o conceito de violência proporciona significados heterogêneos e, ao mesmo tempo, necessariamente polissêmico nas análises contextuais. Daí a grande dificuldade de uma metodologia para a interpretação do fenômeno. Ademais, como as variantes temporais determinam a manifestação diferenciada das formas de violência para cada sociedade, é importante precisar as formas e tipos que assumem para cada contexto histórico, bem como sua tolerância social e os limites do que seja legal e ilegal. Certamente, as análises sobre o fenômeno da violência e da criminalidade tem buscado cada vez mais uma interpretação em longa duração para o entendimento do fenômeno percebendo a interligação cultural, para além dos aspectos econômicos e políticos. Isto proporciona verificar a permanência da aceitabilidade do fenômeno para uma dada sociedade, independente do viés da legalidade do uso da violência.

Assim, a proposta deste dossiê é divulgar os trabalhos dos pesquisadores que percebem a violência e a criminalidade em seu contexto histórico diferenciado, contribuindo para fomentar estudos na temática, além de proporcionar maior visibilidade ao grupo de pesquisa História Social do Crime e seus membros, bem como de outros estudiosos sobre a temática da criminalidade. A contribuição do dossiê 'História Social do Crime' para a historiografia criminal está na proposta de trabalhos que ofereçam a problematização da criminalidade e da violência num diálogo interdisciplinar e atual, buscando nas vertentes teóricas da Teoria da Privação, quanto da Escola de Chicago ou da vertente da história cultural a ampliação da discussão do nosso objeto de pesquisa.

A História Social do Crime, uma vertente da Historiografia Inglesa orientada para as pesquisas sobre a temática da criminalidade, a formação dos bandidos e dos motins na Inglaterra iria contribuir para uma profusão de trabalhos sobre o tema, e que ainda são registros para as análises de quaisquer trabalhos. Um dos argumentos centrais nesta perspectiva de análise demandou estudos exaustivos sustentados pela relação pobrezacrime. A criminalidade seria analisada a partir do processo de exclusão social, pauperização e desigualdades econômicas, que inevitavelmente incidiam sobre as classes operárias e o 'lumpem' proletariado. A proposta foi apurada pela Tese da Privação 
Relativa $^{\mathrm{I}}$ e Absoluta ${ }^{2}$, ainda vigentes para o entendimento da criminalidade nas sociedades modernas.

Já, no início dos anos 90, as análises da violência interpessoal e do crime concentraram-se num diálogo com a vertente francesa da Escola dos Annales, buscando desta forma contribuir com elementos diferenciados para o tema. A importância da cultura e dos aspectos rituais seriam valorizados, frente a dinâmica do conflito de classes. Metodologicamente a violência seguiria uma proposta a partir de dois modelos interpretativos e interdependentes: a violência instrumental (racional) que se traduz enquanto abordagem quantitativa. Ou seja, consideram-se apenas os índices de homicídios como indicação do grau de violência nas sociedades passadas. Um aumento ou declínio da proporção de homicídios nas dadas culturas traduz-se em resultados variáveis nos níveis de violência. A outra abordagem qualitativa, por sua vez, situa-se no estudo da violência impulsiva e suas variáveis culturais. A ênfase da pesquisa qualitativa situa-se no campo do comportamento moral e ritual dos indivíduos; assim como o significado contemporâneo atribuído aos atos violentos.

Segundo Spierenburg ${ }^{3}$, a obra de Natalie Davis foi pioneira neste tipo de estudo. Ao analisar a violência enquanto ato simbólico para a purificação da comunidade francesa no século XVI, Davis buscou não apenas constatar um fato histórico, mas problematizar a manifestação da violência inserida dentro de um código moral religioso. Os estudiosos dessa linha têm proclamado que, até meados do século XVIII, a vida social dos indivíduos, suas atitudes e comportamentos eram moldados de acordo com as normas de conduta e as regras morais que caracterizavam o Antigo Regime, cujo teor valorativo se evidenciava tanto nos laços amorosos, quanto nas relações de ódio.

A partir daí elementos culturais passaram a ocupar as análises da violência cotidiana nas sociedades europeias pré-industriais, relacionando-a aos conceitos de honra, infâmia, os insultos e até as celebrações festivas vigentes em sua época. Também, as análises de Pieter Spierenburg, Ted Gurr, Juian Pitt-Rivers, Robert Muchembled, Gregory Hanlon, Paul McLean, Jon Elster, Alan Hamlin, e outros têm possibilitado uma nova interpretação sobre a manifestação da violência interpessoal e da criminalidade no século XVIII, cujos resultados demonstram uma relação íntima entre a agressividade humana, o

\footnotetext{
${ }^{\text {I }}$ MERTON, Robert. Estrutura Social e Anomia. In.: Sociologia: teoria e estrutura. São Paulo: Mestre Jou, 1968. APUD: BEATO, Cláudio. Crime e Cidades. Belo Horizonte: UFMG, 2012. pp.: I44-I45.

${ }^{2}$ MESSNER, S. "Income Inequality and Murder Rates: Some Cross-sectional Findings". In.: Comparative Social Research, I980. APUD: BEATO, Cláudio. Crime e Cidades. Belo Horizonte: UFMG, 20I2. pp.: I44-I45.

${ }^{3}$ SPIERENBURG, Pieter. Faces of Violence: Homicide trends and Cultural meanings: Amsterdam, I43I-I8I6. Journal of Social History. 1994, pp. 70I-7I6.
} 
conflito e a exigência em se manter um espaço de aparências sustentado pela honra e pela virilidade masculina. A conduta violenta dos indivíduos objetivava não apenas a manutenção de uma posição de destaque frente aos demais. Buscava-se, antes de tudo, a distinção pessoal.

A importância do contexto histórico deve-se à capacidade em se perceber os elementos valorativos e as formas culturais que contribuem para a manifestação ou perpetuação das formas da violência. A descoberta dessas noções valorativas possibilita um novo entendimento das formas mais corriqueiras do viver em sociedade e a conjugação destas com a manifestação da violência, constatando-se não apenas os fatos históricos cruéis e sangrentos, mas uma trama histórica intimamente relacionada com as necessidades do homem. Essa violência ritual manifestava-se tanto nos crimes passionais tidos como racionais, já que o assassino elaborava um cálculo racional para cometer tal ato (mormente cometidos contra as mulheres infiéis em dias significativos, como o de Santa Maria Madalena), quanto em duelos e rixas familiares. Tais crimes eram classificados como atos impulsivos, cujo objetivo era o de lavar com sangue a honra dos envolvidos. Com feito, tanto a violência racional, que possui uma orientação estratégica de meios e fins, quanto à violência impulsiva podem, de acordo o com contexto histórico, orientar-se, cada qual, por um código ritual e moral das comunidades.

Elementos culturais como moral, ética, rituais, elementos simbólicos, as noções do lícito e o ilícito podem (e devem) ser utilizados na análise dos incidentes violentos de uma determinada sociedade, como defende Pieter Spierenburg (1994). Porém, para este pesquisador, a tendência atual é a de uma marginalização crescente dos aspectos rituais da violência e uma ênfase progressiva no caráter instrumental da ação violenta, já que a produção recente tem elaborado análises superficiais e meramente estatísticas, que não respondem à complexidade de tal fenômeno. Pois, a análise da violência exclusivamente abordada em seu caráter quantitativo, através de indícios documentais judiciais, apresenta inúmeros problemas: veracidade das fontes, poucos indícios, mudanças nas atitudes públicas de repressão e nos padrões dos crimes cometidos, aumento da população, sem mencionar as variações da economia, que influenciam as atitudes de sobrevivência dos agrupamentos humanos.

A História Social do Crime considerava importante as análises sobre as classes excluídas, demandando não apenas uma outra metodologia mais quantitativa, como também identificando as rupturas sociais nas mudanças da criminalidade. $\mathrm{O}$ historiador 
inglês, Lawrence Stone ${ }^{4}$, a este exemplo, ao analisar a violência interpessoal na Inglaterra entre os anos de 1300 a I980, constatou tanto uma mudança na atitude pública perante o crime, quanto a publicação de novas leis e uma maior sensibilização da população, influindo negativamente nos índices da agressão. O autor concluiu que a introdução de uma força policial no século XIX na Inglaterra foi responsável pelo declínio da violência e da agressão ${ }^{5}$. Autores que se inserem nessa perspectiva são sustentados pela tese de Norbert Elias (1994) sobre o processo civilizador e reiteram, através de evidências documentais, um acentuado declínio dos homicídios a partir do século XVII e que se estende até o Oitocentos. O que só foi possível pela implementação de políticas públicas de ordenação do tecido social e aumento da força policial. Notadamente, a monopolização da violência se fez pela atuação crescente do Estado, acompanhada pela organização de uma força policial e por um processo sócio psicológico de pacificação do instinto agressivo.

O dossiê pretende abranger os estudos sobre a violência e a criminalidade, apresentando trabalhos inéditos tanto relacionados ao contexto histórico do país, quanto análises pertinentes para outras realidades exteriores que possam contribuir para o entendimento do fenômeno criminal.

Neste sentido, os trabalhos apresentados suprem de maneira brilhante o nosso objetivo. A temática busca a compreensão do crime nas suas várias manifestações através dos diferentes contextos históricos apresentados. Assim, a dimensão do estudo da criminalidade está abordada em várias regiões do país e em diferentes contextos históricos, desde o século XVIII ao século XX. O rigor metodológico e teórico é identificado em cada trabalho, bem como o cuidado com as fontes documentais e bibliografia atualizada. A percepção historiográfica dos trabalhos apresentados conta com as abordagens culturalistas e da história social. Contamos neste número com pesquisas de vários estados brasileiros, possibilitando o diálogo entre os membros do Grupo.

\footnotetext{
${ }^{4}$ STONE, Lawrence. Interpesonal Violence in English Society: 1300-1980". Past \& Present. 1983. Pp. 22-33.

5 Jean-Claude Chesnais, ao contrário, irá perceber a manifestação da violência como uma ação invariavelmente objetivada sobre as famílias. Sem se preocupar com estes modelos explicativos de aumento ou diminuição na incidência de crimes, Chesnais apenas constata a permanência da violência nas sociedades ocidentais e suas múltiplas formas de manifestação em cada momento histórico. Com efeito, as famílias, estes pequenos núcleos humanos, sempre foram afetados em sua constituição íntima pelo ódio humano em todas as épocas históricas. A desestruturação dos lares se dá seguramente pela violência incontrolável que os margeia, justificada tanto pela fome quanto pela idolatrada honra nos séculos passados. Cf.: CHESNAIS, Jean-Claude. Historie de la violence. Seiul. Paris, 1998. Beattie, por sua vez, defende um aumento na proporção dos crimes durante o século XVIII na Inglaterra graças a criação da 'Reformation of Nauners', cujo objetivo era ajudar a conter os crimes e demais desordens e violências. Porém, o resultado foi outro. Pois, a extensão da pena de morte para os homicídios contra a propriedade e outros atos violentos considerados insignificantes no período posterior, levou a um aumento gradual tanto dos registros das prisões, quanto dos julgamentos nos tribunais. Cf.: BEATTIE, F. M. The pattern of crime in England. I660-I80o. Past and Present. 62. Pp. 45-95.
} 
Optamos por uma organização cronológica dos trabalhos selecionados para esta coletânea. Assim temos: "O Preciso e a retórica dos revolucionários de I8I7" de Flávio José Gomes Cabral, onde o autor analisa o discurso revolucionário pela divulgação do panfleto 'Preciso', que aludia a justificativa revolucionária da época. A seguir: "Punição, regeneração e autonomia: aspectos do trabalho prisional vistos a partir da fuga do 'preto Thomaz' (Recife, I868)” de Aurélio de Moura Britto. O texto faz uma análise sobre o sistema prisional da época, seus regulamentos e prescrições da vida na Casa de Detenção de Recife a partir de um estudo de caso. O artigo a seguir: "Salve-se quem puder": as faces da criminalidade no Recife na década de $\mathbf{1 8 7 0 "}$ de Jeffrey Aislan de Souza Silva analisa a criminalidade na cidade de Recife como um problema político para as elites locais. Também, “'Grandes desejos”, realidades distintas: roubos e furtos no Recôncavo Baiano - Cachoeira, década de I880" do autor Eliseu Santos Ferreira Silva busca analisar as práticas de furtos e roubos no Recôncavo Baiano durante a década de 1880 compreendendo essa prática ilegal e o meio social em grande transformação, bem como as formas de combate da infração na época por parte das elites políticas locais. A seguir: "Os jornais cariocas e as notícias de homicídios na primeira década do século XX", de Thiago Torres Medeiros da Silva. A abordagem busca perceber a divulgação dos homicídios em jornais da época, analisando suas formas de narrativas e linguagens jornalísticas para o fenômeno. Também, o texto: "As aparências enganam: mulheres e o uso da imagem para prática de crimes contra a propriedade no Rio de Janeiro da Primeira República" de Aline Carneiro do Nascimento versa sobre a análise de crimes cometidos por mulheres brancas, bem como a forma de narrativa destes crimes e suas as reportagens nos jornais da época. Outro artigo: "O Batman tinha uma arma: influências sócio-políticas da construção da moral do arquétipo na década de 1930", de Sávio Queiroz Lima, busca analisar a construção de uma conduta moral a partir de personagens ficcionais de histórias em quadrinhos da época. Assim, a representação de Batman é emblemática para se perceber a efetivação de uma política norte-americana de combate às armas e ao crime organizado, estendendo-se aos países de sua influência hegemônica no período. A seguir, o artigo: "Piratas do Rio: roubos, furtos e outros crimes a bordo e nas margens da Região de Manaus", de Leno José Barata Souza. O autor analisa a prática da criminalidade na Região de Manaus durante o século XX a partir de jornais da época. Manaus, conhecida como a 'cidade dos piratas' foi palco, durante o período, de uma das formas mais emblemáticas de criminalidade: a pirataria contemporânea. $\mathrm{O}$ autor analisa este fato levando-se em conta a 
grande transformação da economia do lugar, bem como as questões sociais que influenciaram o fenômeno na região.

Prof $^{a}$ Dra Célia Nonata da Silva (UFAL)

Prof. Dr. Francisco Linhares Fonteles Neto (UERN)

Organizadores do dossiê História Social do Crime 